\title{
Habit reversal following single-alternative training and partial reinforcement'
}

ELIZABETH VAN LAER, Department of Psychology, The City College, CUNY, N. Y., 10031 and NICHOLAS PASTORE, Department of Psychology, Queens College, CUNY, N. Y. 10067

Percentage of reinforcement (100\% vs 50\%) had no effect on acquisition or reversal scores of 48 rats trained in a T maze. The Ss with previous exposure to both arms of the maze made more errors during reversal than Ss that had not been permitted entry during acquisition to the arm that was correct during reversal. Running speed data showed no differences among groups.

The partial reinforcement extinction effect (PRE) has been obtained in selective learning situations that use habit reversal (Brunswik, 1939; Grosslight \& Radlow, 1956) rather than extinction by omission of reinforcement. The interest of the present experiment was in the effect of PR during acquisition on habit reversal of Ss that had received single-alternative training; i.e., they had not been permitted entry during acquisition to the arm of a T maze that was correct on reversal trials. Pastore (1964), using a similar design, obtained a reversed PRE in canaries. The general hypothesis is that an unreliable alternative will be readily given up when a reliable alternative, one that has not been associated with nonreinforcement, is presented. Single-alternative training was expected to produce equally rapid reversal in $P R$ and CRF Ss. In addition, it was expected that these Ss would reverse more rapidly than $S s$ that had received conventional doublealternative training, i.e., that had been permitted entry to both arms of the maze during acquisition. Reversal results of CRF and PR groups following double-alternative training were expected to yield the conventional PRE.

\section{METHOD}

The Ss were 48 naive male albino rats, weighing $200-250 \mathrm{~g}$ at the start of training. The Ss were placed on a 23-h water deprivation schedule (food ad lib) two weeks prior to training; they were handled twice daily during this period. The deprivation schedule was maintained throughout the experiment.

The apparatus was a single unit $\mathrm{T}$ maze with 20 -in. arms and stem. Plexiglas doors at the choice point prevented retracing. The door was opaque when entry to an arm was blocked. Cloth curtains located $12 \mathrm{in}$. beyond each door screened the entrance to the goal box. A water cup was located in the goal box when reinforcement was scheduled.

Preliminary training was minimal; on each of two days S spent 2 $\min$ in the stem of the maze.

The Ss underwent 50 acquisition trials by the noncorrection method, 10/day for five consecutive days. The intertrial interval was $15 \mathrm{sec}$. The goalbox time was $10 \mathrm{sec}$. Running time, obtained with a stop watch, was the time taken by $S$ to proceed from the maze entry to a goalbox curtain.

There were four groups of $12 \mathrm{Ss}$ each. Double-alternative (DA) Ss could turn right or left at the choice point, whereas single-alternative (SA) Ss could turn into one arm only; the other arm was blocked at the choice point. The DA and SA groups were each divided into a $100 \%$ and $50 \%$ reinforcement subgroup. The correct goalbox was baited on $100 \%$ of the trials for both the 100DA and 100SA subgroups and on 50\% of the trials for both the 50DA and 50SA subgroups. The PR schedules, determined independently for each $S$, were random except that there were no more than two reinforced or nonreinforced trials in a row. The first and last trial of each day was reinforced, following a pattern Grosslight \& Radlow (1956) found to maximize PRE. Half of the Ss of each group found water in the right-hand goalbox and half in the left-hand goalbox.

The Ss completed 40 reversal trials, 10/day for four consecutive days. The water cup was located in the goalbox that was unbaited during acquisition. All Ss were reinforced for every correct response; both arms of the maze were open. The first trial was a correction trial; subsequent trials were noncorrection. Other procedures were the same as in acquisition.

RESULTS

The learning curves of the 100DA and 50DA groups were parallel throughout acquisition, as can be seen in Fig. 1. The 50DA group was slightly superior to the 100DA group on all days; the mean difference was less than one-half correct response. The difference in mean total correct responses did not appraoch significance $(p>.10)$. An analysis of log total running times for each $S$ on Day 5 of acquisition revealed no significant effect of number of alternatives or of $P R$, and no interaction between the two ( $p>.05$ in all tests).

Figure 1 shows that the reversal functions were steeper than the acquisition functions for all groups. There was no effect of PR on correct responses made during reversal; the mean total correct responses for the $100 \%$ and $50 \%$ groups were identical. There was no significant interaction between PR and number of alternatives ( $p>10$ ). Mean correct responses was significantly greater for the SA groups than for the DA groups $(F=7.49$, $\mathrm{df}=1 / 44, \mathrm{p}<.01$ ). The SA and DA groups reversed at different rates, as indicated by a significant interaction between alternatives and days $(F=8.10$, $\mathrm{df}=3 / 132, \mathrm{p}<.01)$. The difference between SA and DA in rate of reversal was most prominent early in reversal (Fig. 1). It is noteworthy that on Trial 2, 22 Ss in SA made correct responses whereas only three Ss in DA did so.

There was no significant effect of alternatives or PR on $\log$ running times on the first day of reversal ( $p>.10$ in all tests). Most Ss ran slower on the first day of reversal as compared with the last day of acquisition, but there were no significant differences among groups in proportional increase in running times ( $p$ > 10 in all tests).

\section{DISCUSSION}

Exposure to only one alternative during acquisition facilitated reversal when correct responses were the measure. It is reasonable to suppose that both an associative component and a motivational component contributed to this effect. Nonreinforcement of incorrect responses made by the DA Ss during acquisition reduced the probability that these same responses would be made on reversal trials. In addition, the observation that the SA Ss made many more correct responses on the first two reversal trials than the DA Ss suggests that exploratory tendencies may have been operating.

The present results failed to show any evidence for a PRE, either in choice or speed scores. This result was predicted for the SA groups; however, a PRE was expected in a comparison of the DA groups, which had completed relatively standard training. The PRE, although common, is not uniformly reported in T-maze

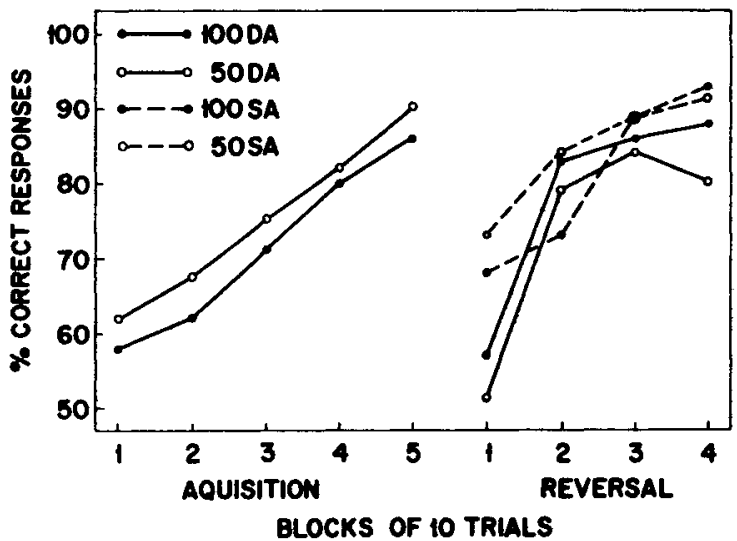

Fig. 1. Mean per cent correct reeponses during sequisition and reversal. 
keaning (Denny. 1946). A recent vedy showed resistance to cxtiliction unrelated to PR (Uh/ \& Foung. 1967 ). The fature to ohserve PRE in this experiment does not seem to be attributable to excessive variability. Mean correct responses for the $100 \%$ and $50 \%$ subgroups, under both DA and SA, were remarkably similar on all days of reversal training. Only one of the eight such comparisons yielded a difference in means as large as one correct response. Even if a PRE were statistically detectable for these dati. its magnitude would be trivial.

In interpreting Pastore's (1964) experiment, where a similar procedure produced a reversed PRF, Amsel $(1964)$ suggested that anticipatory frustration is conditioned to approach responses only after many trials. This argument cannot account for the present results, which are based on 50 acquisition trials, since 30 trials are sufficient to produce a PRE in T-maze learning (Brunswik, 1939; Cotton et al, 1959).

Studies that show a PRE in nonspatial habit reversal generally report slower reversal than occurred in the present study. Typically, performance is below $50^{\prime} \%$ mean correct responses in the early trials (Grosslight \& Radlow, 1956). In the present experiment, no group was below $50 \%$ correct responses on Day 1 of reversal, and all groups achicved at least $70 \%$ correct on Day 2. The absence of a PRE in the present results may be attributable to the rapid reversal that was observed.

\section{REFI:RI:NCI:S}

AMSII. A Comment on cognitive interpretation of PRI in a discrimination situationt. Perceptual \& Motor Skills, 1964, 19.924.

BRIINSWIK. I: Probability as a determiner of rat behavior. Journal of Experimentat Psychology, 1939, 25, 175-197.

COTTON, J. W., LEWIS, D. J., \& JENSEN, (i. D) Partial reinfucement effects in a T maze. Journal of Comparative \& Physiological Psychology. 1959. $52.730-7.3 .3$.

DINNY. M. R. The role of secondary reinloncement in a piltial reinforcement learning situation. Joumal of Experimental Psycloology, $1946,36,373-389$.

GRoSSllitit, J. H., \& RADLOW, R. Palleming effect of the nonreinforcenent-reinforement sequence in a discrimination situantun. Jountial of Comparative \& Physiological Psychology . 1956, 49, 542.546,

PASTORL . N. Cognitive interpretation of PRI: in a discrimination situation Pretiminary report. Perceptual \& Motor Skills, 1964, 19, (187-6900.

UIIL. C. N.. \& YOUNG, A. G. Resistance to extinction as a function of incentive, perectage of reinforcement, and number of nonreintiored trials. Journal of Experimental Psychology, 1967, 73, 556-50t.

\section{NOTE}

1. This research was supported in part by Grant MH 05877.03 of the National Institutes of Health. 